Article

\title{
Sustainable Smart Healthcare Information Portfolio Strategy Evaluation: An Integrated Activity-Based Costing Decision Model
}

\author{
Chih-Hao Yang ${ }^{1, *}$, Hsiu-Li Lee ${ }^{2}$, Wen-Hsien Tsai ${ }^{3}$ and Sophia Chuang ${ }^{3}$ \\ 1 Department of Financial Management, National Defense University, Beitou, Taipei 11258, Taiwan \\ 2 Department of Accounting Information, Chihlee University of Technology, New Taipei City 22050, Taiwan; \\ lee05301@mail.chihlee.edu.tw \\ 3 Department of Business Administration, National Central University, Jhongli, Taoyuan 32001, Taiwan; \\ whtsai@mgt.ncu.edu.tw (W.-H.T.); 108481011@cc.ncu.edu.tw (S.C.) \\ * Correspondence: chyang@ndu.edu.tw
}

Received: 16 November 2020; Accepted: 10 December 2020; Published: 20 December 2020

\begin{abstract}
Smart city and smart hospital development comprise a mainstream strategy worldwide to enhance the achievement of Sustainable Development Goals (SDGs) and Corporate Social Responsibility (CSR) practices. The smart healthcare industry needs to optimize its smart healthcare information strategies, creating the process-activity value and reducing the cost of healthcare without sacrificing the quality of patient care. This study proposes an decision model of Activity-Based Costing (ABC) concept and Multi-Criteria Decision-Making (MCDM) techniques that integrates the Decision-Making Trial and Evaluation Laboratory (DEMATEL), Analytic Network Processes (ANP), the VlseKriterijumska Optimizacija I Kompromisno Resenje (VIKOR) and Zero-One Goal Programming (ZOGP) to achieve optimal smart healthcare information system portfolio strategy decisions. The resulting data shows that the perspective of government policy support and the criterion of Minimize Equipment Maintenance Costs are the most significant evaluation factors, and that the Health Data Informational System and Hospital Device and Drug Management System comprise by far the optimal portfolio of smart healthcare information system which strengthen the connection between $\mathrm{ABC}$ and MCDM techniques in evaluation process. The major contributions of this study are as follows: (1) the proposed model contributes to the management accounting innovation development of a sustainable city and Operation Research (OR) application; (2) the integrated model can promote the smart healthcare industry development and help decision makers to more accurately understand how to allocate resources and planning for intelligent-related activities to each smart healthcare information system through appropriate cost drivers.
\end{abstract}

Keywords: sustainable development; Activity-Based Costing (ABC); smart healthcare information system; multiple-criteria decision making (MCDM); mathematical programming; resource constraints

\section{Introduction}

The World Health Organization (WHO) (2008) identified that "eHealth is the cost-effective and secure use of information communication technologies (ICT) in support of health-related fields, including healthcare services, health surveillance, health literature, and health education and research" [1]. The government health policy, essential to achieving the Sustainable Development Goals (SDGs), is the important foundation for the eHealth industry chain development that will promote better healthcare services for the population. Recent advances in the application of big data technologies, including electronic health record systems (EHR), picture archiving and communications systems (PACS), and healthcare data value-added service platforms, etc., are arising in smart healthcare 
information system (SHIS) implementation [2]. Hence, the decision maker of a smart hospital needs to consider the human orientation of a smart healthcare information strategy to realize both the optimization of the hospital operation process and the improvement of the Doctor-Patient Relationship.

The focus of the evaluation regarding healthcare information differs based on the smart hospital's development objectives. Simultaneously, the ICT fundamental facility should incorporate the cost planning and resource allocation to provide the maximum benefits for hospital operation management. Sligo [3] propose that organizational, technological and human factors impact the effectiveness of healthcare information system implementation. Therefore, the multidimensional characteristics of smart healthcare information system selection are facing the challenge of complexity, solving the decision problem appropriately by combining the advantages of the multiple-criteria decision-making (MCDM) methods, management accounting techniques (such as Activity-Based Costing) and the Mathematical Programming (GP) model. Existing studies have confirmed the feasibility of applying the MCDM model combining the Decision-Making Trial and Evaluation Laboratory (DEMATEL), the Analytic Network Process (ANP) and VlseKriterijumska Optimizacija I Kompromisno Resenje (VIKOR) in decision problem evaluation, such as reliability-based product optimization [4], sustainability performance evaluation [5], and food waste composting facilities [6] (Liu et al., 2018), and so on.

Sustainable smart healthcare information portfolio strategy development is an important niche segment that activates innovation in smart hospital technology and bridges the gaps among academia, research, and industry. Clearly, the national healthcare policy can promote the development of optimal smart healthcare information strategy portfolios from the smart hospital, thereby ensuring accurate cost measurement, and accelerating the promotion of sustainable smart healthcare economic benefits. Therefore, the evaluation of smart healthcare information system strategy cost and combine the advantage of mathematic programming can help to increase the policy practices and sustainable development goals However, little research to date has combined the MCDM and management accounting technology to measure smart healthcare information system implementation. In order to achieve smart healthcare management efficiency, it is necessary to evaluate the interrelationship among various criteria. The proposed hybrid model combines smart healthcare information strategy evaluation criteria and Activity-based costing $(\mathrm{ABC})$ and considers resources requirements, including budgets, process improvement percentage, and implementation period, according to the specified activity level categories. The purpose of this study is to develop a hybrid decision model for the smart healthcare information strategy decision-making optimal portfolios by applying a combination of activity-based costing, multi-criteria infrastructure, and mathematical programming.

\section{Literature Review}

This section presents recent, relevant literature on smart healthcare information system selection problems showing an integrated decision model that incorporates evaluation criteria, and Activity-Based Costing concepts.

\subsection{Smart Healthcare Information System}

Smart city policy is a government-promoted scheme that connects the individual, the environment and city infrastructures using ICT in order to create an intelligent, sustainable and innovative life $[7,8]$. Especially in smart hospital development, eHealth is an important trend toward providing various reliable, strong healthcare services. The smart healthcare information system (SHIS) becomes increasingly critical for clinical care and hospital operations. Smart cities as engines for growth in Asia, which The Policy Note of OECD [9] reports policy makers to engage in efforts to make their cities "smarter" in several countries, Smart healthcare technology offers new solutions for citizens. Haux [10] indicates that the essentials of a healthcare information system are computer-based processing and data storage, as well as promoting doctors' professionalism effectively and improving the operational process. Currently, the smart healthcare information system is widely applied, with some of its common components including electronic health records (EHR), picture archiving and communication systems 
(PACS), chronic disease management systems, and medical device and drug management systems, etc. [11]. In Taiwan, the government has proposed various policies, regulations, and incentives to encourage the development of the smart healthcare information industry, particularly in regard to the smart hospital. Evaluation of the smart healthcare information system and reasonable resources allocation are complex; therefore, the decision maker must pay attention to various assessment standards in the implementation of the system project.

\subsection{The Evaluation Criteria of the Smart Healthcare Information System}

This study proposes critical perspectives and criteria upon which to focus: Smart Technology Innovation (STI), Healthcare Value Creation (HVC), Financial Management Benefit (FMB), and Government Policy Support (GPS).

Smart Technological Innovation (STI) for the smart healthcare information system must also emphasize the healthcare data platform, innovation application and user acceptance with usefulness. Zhang et al. [12] indicated that there are challenges for healthcare-related data management, storage, and processing, including the large scale, varied structures, and deep value; therefore, the smart healthcare information system must provide the healthcare data analysis functional module to create the maximum data value. Tuli $S$ et al. [13] also presented that large computation power is costly, which makes the affordability of healthcare for all; On the other hand, the innovation of healthcare service focuses on building the co-creative paradigm and integrating the requirement of the internal and external stakeholders [14], such as telecare, eLearning of health education, etc. Handayani et al. [15] utilized the Technology Acceptance Model (TAM) to investigate the users' opinions of both the ease of use and the benefits of the hospital information system, and proposed incorporating the human and organizational characteristics into smart healthcare information system decision assessment.

Healthcare Value Creation (HVC) is divided into business value creation and the doctor-patient relationship. Wang et al. [16] propose a big data analytics-enabled transformation model to adopt business values through the implementation of the healthcare information system, and presented a benefit dimension (including operational, organizational, managerial and strategic evaluation) that contributes to business value. More importantly, the improvement of the Doctor-Patient Relationship is a medical essential of a smart hospital. Liang et al. [17] indicate that a patient-accessible healthcare information system promotes patients' perception of service fairness, improves doctor-patient relationships, and increases patient satisfaction. Therefore, the various services of smart healthcare information technology benefit the doctor-patient relationship quality and patient satisfaction.

Financial Management Benefit (FMB) is one of the evaluation perspectives for a smart healthcare information system. Cost management is a crucial challenge to information system implementation and achieves the cost-effectiveness maximum by improving efficiency [18]. From the life cycle concept of an information system, the SHIS cost category should consider the initial investment cost, operational cost, and maintenance cost [19]. Ker et al. [20] propose that the adoption of SHIS has certainly improved the healthcare service process, significantly reducing the relevant cost through care delivery, medical error prevention, and clinical care improvement, respectively. Therefore, reasonable budget planning and controlling a smart healthcare information system will lead to successful adoption and implementation.

With regard to the smart industry regulatory environment, government policy support has a powerful impact on the strategy and diffusing of smart technology [21]. Government Policy Support (GPS) of smart healthcare includes a financial subsidy policy and user privacy protection. Ahmadi et al. [22] provide a useful analytical framework and indicate that the government subsidies assistance is an incentive instrument for a health information system to continue making the hospital sustainable operationally. In addition, WHO [23] indicated that a well-run regulatory environment is the steady basis for eHealth development, especially in the adoption of health data privacy legislation. As a practical implication, in order to foster the adoption of SHIS, government needs to provide a regulatory environment and proactive support with financial resources for smart healthcare industry development to be contributed to public and private hospitals. 


\subsection{Smart Healthcare Information System Budgets Planning Assessment: The Activity-Based Costing $(A B C)$ Concept}

Traditional cost systems mainly use direct material and labor to allocate overhead costs. In the emerging information communication technology industry, the traditional cost system using only direct labor costs as a primary apportioning source can cause significant cost distortions and information resulting in improper decisions. Cooper and Kaplan [24] provide improved accuracy of product cost information in terms of the Activity-Based Costing $(\mathrm{ABC})$ technique. To overcome the traditional cost system insufficiency, $\mathrm{ABC}$ assessment mainly includes processes and activities with cost characteristic identification as the intermediary of cost assignments, which enhances the transparency of business operation cost information.

$A B C$ has been widely used in various smart city-related and healthcare areas, such as the UK's manufacturing sector's innovation adoption, the cost estimation of anesthesia care, and identifying the inefficiencies related to the healthcare process, etc. [25-27]. This study incorporates the ABC technology into the SHIS investment budget planning process. Simultaneously, with regard to the SHIS project as cost objects, this study employed the information system implementation phase to identify and classify activities related to the system cost. In the first stage, resource costs are directly traced by resource drivers. The factors are chosen to approximate the consumption of resources used in SHIS implementation activities to activity cost pools. Each type of resource traced to an identified activity becomes one cost element within an activity cost pool that can be classified by activity levels, such as unit, batch, project and artificial intelligence, respectively. Each activity level can have several activity cost pools in which costs are accumulated to a single activity in the ABC system. In the second stage, the costs in the activity cost pools are assigned to the SHIS project (cost objects) by proper activity drivers where activities incur costs.

As a general rule, the total costs of SHIS are divided into direct and indirect cost dimensions. The direct costs are material and labor costs; the indirect costs relate to the IT project and artificial intelligence issues. Moreover, the information system life cycle concept integrates with the $A B C$ technique to identify the proper activity and its drivers, including the initial design phase, the installation phase, the operation phase, and the improvement phase, respectively. The indirect costs consider the intelligent-related classification, as shown in Table 1.

Table 1. The activities classification of the SHIS life cycle phase.

\begin{tabular}{|c|c|c|c|c|}
\hline & SHIS Life Cycle & Activity & & Activity Level \\
\hline \multirow[b]{2}{*}{ I } & \multirow{2}{*}{ Initial design phase } & Planning design activity & {$[\mathrm{P}]$} & Project-level \\
\hline & & Network environment activity & [A] & Artificial intelligence level \\
\hline \multirow[b]{2}{*}{ II } & \multirow{2}{*}{ Installation phase } & System installation activity & [U] & Unit-level \\
\hline & & Staff training activity & [B] & Batch level \\
\hline \multirow{2}{*}{ III } & \multirow{2}{*}{ Operation phase } & Maintenance and repair activity & [U] & Unit-level \\
\hline & & Data analysis activity & [A] & Artificial intelligence level \\
\hline \multirow{2}{*}{ IV } & \multirow{2}{*}{ Improvement phase } & System module upgrade activity & [U] & Unit-level \\
\hline & & Management platform activity & [A] & Artificial intelligence level \\
\hline
\end{tabular}

\section{Methodology of the Integrated Approach}

In this section, this hybrid MCDM model established using the qualitative and quantitative domains is deemed to be a suitable technique for the exploration of issues related to sustainability for a smart healthcare information systems. The hybrid model is a powerful tool that help to identify the effect relationship between evaluate factors and have be widely used to analyze policy measurement. The various steps of this hybrid model are detailed below:

Step 1: Evaluating relationships among the perspectives and criteria with DEMATEL

Step 2: Evaluating priority weight among the criteria by ANP. 
Step 3: Based on the VIKOR approach and rank alternatives.

Step 4: The direct costs and allocation of indirect costs according to ABC

Step 5: An optimal portfolio for the smart healthcare information system project using the Zero-One Goal Programming Model.

This is followed by a detailed methodology introduction, which is explained in the next section.

\subsection{Decision-Making Trial and Evaluation Laboratory (DEMATEL)}

The Science and Human Affairs Program of the Battelle Memorial Institute of Geneva developed an approach, the DEMATEL [28]. Mainly, the DEMATEL approach illustrates the interrelationships of criteria concerns and constructs network relationships. The following steps describe the DEMATEL method: (1) Calculation of the direction-relationship matrix; (2) Normalization and analysis of the direct-relation matrix and total-relationship matrix; (3) Finding the cause and effect groups and setting the threshold values to obtain the impact path relationship. The threshold value is determined through average value or discussion with the decision makers and groups of experts. Accordingly, the relationship of evaluation perspectives (Smart Technology Innovation, Healthcare Value Creation, Financial Management Benefit, and Government Policy Support) will be proposed and will determine the network of analysis.

\subsection{The Analytic Network Process (ANP)}

In order to explore the relationship among the perspectives and criteria, Satty proposed the ANP method. Different from the Analytic Hierarchy Process (AHP) method, the ANP is able to release the restrictions between complex decision levels of the hierarchical structure. The following steps describe the ANP method:

(1) Establish the analytic network and calculate the priorities of the perspective and criteria; (2) Analyze the pairwise comparisons with criteria for a priority weight matrix and conduct a consistency test.

The matrix can be accomplished by the pairwise comparisons resulting from the experts' questionnaire. The general form of the matrix $U$ can be described as Equation (1):

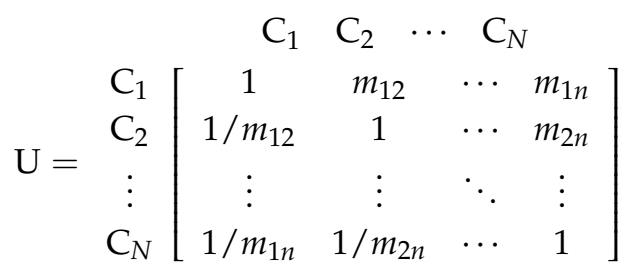

In matrix $\mathrm{U}$, the problem becomes one of assigning, to the $\mathrm{n}$ criteria. A set of numerical weights, represents the expert judgments. Saaty [29] suggests that the largest eigenvalue would be as presented here Equation (2):

$$
\lambda_{\max }=\sum_{j=1}^{n} m_{i j} w_{j} \mid w_{i}
$$

Finally, the consistency of judgments by decision makers CI and CR through the value of a consistency index is shown in Equation (3):

$$
C I=\left(\lambda_{\max }-n\right) /(n-1), C R=C I / R I
$$

The random index (RI) indicates the average consistency index of numerous random entries of the reciprocal matrices. If CR is less than 0.1, the outcome of the pairwise comparison is acceptable; if $\mathrm{CR}$ is greater than 0.1, the result presents the pairwise criteria for comparison again. Based on the relationships with the supermatrix, this study set out to obtain the weighting priorities of the criteria 
and to realize the interdependence of each criterion. Above all, the DEMATEL combined with the ANP method is widely applied in several academic fields, including the Taiwanese Certified Public Accountant Firms evaluation [26], the application for a strategy map of a balanced scorecard [30] and a sustainable supplier selection [31], among others.

\subsection{The VlseKriterijumska Optimizacija I Kompromisno Resenje (VIKOR)}

The VlseKriterijumska Optimizacija I Kompromisno Resenje (VIKOR) had been introduced as an applicable technique to implement within the MCDM [32]. The compromise ranking method determines the best rating value and the worst rating value for all the criteria. The following steps describe the VIKOR method:

(1) Computing the values of concordance $\left(S_{j}\right)$ and discordance $\left(R_{j}\right)$. They represented the group utility and the individual regret measures for the alternative $a_{j}$, respectively, with the following relations:

$$
\begin{gathered}
D_{j}^{p=1}=S_{j}=\sum_{i=1}^{n} w_{i}\left[\left(x_{i}^{*}-x_{i j}\right) /\left(x_{i}^{*}-x_{i}^{-}\right)\right], \text {for } j=1, \ldots, m \\
D_{j}^{p=\infty}=R_{j}=\max _{i}\left\{w_{i}\left[\left(x_{i}^{*}-x_{i j}\right) /\left(x_{i}^{*}-x_{i}^{-}\right)\right] \mid i=1,2, \ldots, n\right\}, \text { for } j=1, \ldots, m
\end{gathered}
$$

(2) Computing the aggregate value $\left(Q_{j}\right)$.

$$
Q_{j}=v\left[\left(S_{j}-S^{*}\right) /\left(S^{-}-S^{*}\right)\right]+(1-v)\left[\left(R_{j}-R^{*}\right) /\left(R^{-}-R^{*}\right)\right], \text { for } j=1, \ldots, m
$$

(3) Ranking the alternatives by sorting each $S, R$ and $Q$ value in an increasing order. The result was a set of three ranking lists denoted as $\mathrm{S}^{[\cdot]}, \mathrm{R}[\cdot]$ and $\mathrm{Q}^{[\cdot]}$. The best alternative, ranking by $Q_{j}$, was one with the minimum value of $Q_{j}$. The compromise solution could be accepted by the decision makers because it provided a maximum "Group Utility" of the "majority" (with measure $S_{j}$, representing "concordance"), and a minimum of individual regret of the "opponents" (with measure $R_{j}$, representing "discordance").

\subsection{Zero-One Goal Pogramming (ZOGP)}

The ZOGP method, proposed by Charnes and Cooper in 1955 [33], has been applied to many real-world multi-objective problems because it considers limitations of resources. This is characteristic of the goal programming model that focuses on the optimal objective achievement simultaneously to satisfy the various resource limitation conditions. The following describes the ZOGP model:

Minimize $V C=p_{k}\left(w_{j} d_{i}^{+}, w_{j} d_{i}^{-}\right)$

Subject to:

$$
\begin{aligned}
& \sum_{j=1}^{n} r_{i j} x_{j}+d_{i}^{-}-d_{i}^{+}=h_{i} \text { for } i=1,2, \cdots, m j=1,2, \cdots, n \\
& x_{j}+d_{i}^{-}=1 \text { for } i=m+1, m+2, \cdots, m+n ; j=1,2, \cdots, n \\
& d_{i}^{+} \geq 0, \quad d_{i}^{-} \geq 0 \text { for } \forall_{i} \\
& x_{j}=0 \text { or } 1 \text { for } \forall_{j}
\end{aligned}
$$

where $V C$ denotes the sum of the derivation variables from $m$ goals considered; $i$ indicates $m$ restricted resources; $j$ indicates $n$ selected alternatives; $P_{k}$ presents a preemptive priority $\left(\mathrm{P}_{1}>\mathrm{P}_{2}>\mathrm{P}_{3}>>>\mathrm{P}_{k}\right)$ for goal $V C ; x_{j}$ indicates the binary variable of the $j^{t h}$ alternative; $w_{j}$ represents the aggregate value by VIKOR results on the $j^{t h}$ alternative; $r_{i j}$ is the alternative parameter $j$ of the selection resource $I$; and $h_{i}$ denotes the available resources or limitation factors that must be considered in the process of decision making and evaluation. The LINGO 17.0 software (LINDO Systems Inc, Chicago) was employed in this study to calculate the optimal portfolio for smart healthcare information system projects and to determine the deviations between various resource requirements. 


\section{Empirical Case Study of Smart Hospital Information Strategy Planning}

In this section, four smart healthcare information systems of smart hospitals in Taiwan were assessed and ranked to verify the effectiveness and robustness of the proposed MCDM method. For this study, six questionnaires were issued to public hospital center managers. On average, respondents had more than 10 years of seniority.

\subsection{The Smart Healthcare Information System Decision Alternatives}

\section{- $\quad$ SHIS1: Health Data Informational System}

The Health Data Informational System is mainly to manage and integrate information through computer hardware, software technology, and network communication technology; hence, the functions of HDIS include electronic medical records, big data analysis, and the allocation of other resources.

\section{- $\quad$ SHIS 2: Hospital Administrative Information System}

With the Hospital Administrative Information System, the complex hospital administrative process receives the benefits of process integration of health insurance declarations, financial management, and administrative management to improve the administrative efficiency of the hospital and ensure the quality of medical care.

\section{- $\quad$ SHIS 3: Hospital Operation Management System}

The Hospital Operation Management System provides patients with high-quality inpatient care and streamlines the medical care workflow by providing a platform for nursing stations, operating rooms, and outpatient and inpatient departments.

\section{- $\quad$ SHIS 4: Hospital Device and Drug Management System}

The Hospital Device and Drug Management System collects digitized medical products and medicinal materials information, utilizes the smart warehouse management to promote the efficiency of asset inventory and decreases the number of duplicate records.

\subsection{Application of the Integrated Decision Model for the Smart Healthcare Information System Portfolios Strategy}

Step 1: Evaluating relationships among the perspectives and criteria with DEMATEL.

Table 2 shows the perspective relationships of expert decision results, where the threshold value of 2.379 for the perspective was decided, and then the greater-than value was presented so that the column criterion strongly affected the row criterion. According to Table 2, the Government Policy Support (GPS) with the (D + R) score of 20.326 had the highest degree of importance. On the other hand, considering the value of their respective $(D-R)$ scores, the evaluation perspective of Financial Management Benefit (FMB) and Government Policy Support (GPS) were classified into cause group factors, while the Smart Technology Innovation (STI) and Healthcare Value Creation (HVC) belonged with the effect-related groups. 
Table 2. The matrix of the total-relationships of perspectives for SHIS ( $p \geq 2.379$ ).

\begin{tabular}{cccccccc}
\hline & STI & HVC & FMB & GPS & D & D + R & D - R \\
\hline STI & 2.354 & 2.205 & 2.237 & 2.379 & 9.176 & 19.988 & -1.636 \\
\hline HVC & 2.497 & 1.919 & 2.199 & 2.223 & 8.838 & 17.995 & -0.319 \\
\hline FMB & 2.986 & 2.511 & 2.360 & 2.730 & 10.588 & 19.984 & 1.191 \\
\hline GPS & 2.974 & 2.521 & 2.600 & 2.449 & 10.545 & 20.326 & 0.764 \\
\hline R & 10.812 & 9.157 & 9.397 & 9.781 & & &
\end{tabular}

Note: The bold values present the relationship between perspectives that are over the threshold value.

Step 2: Evaluating priority weight among the criteria by ANP.

As shown in Table 3 and Figure 1, once the expert panel's measurement results were obtained, the entire computing process was completed through Super Decision software. The corresponding priorities of the perspectives and criteria formed the unweighted and weighted supermatrix and limiting powers until the weights converged to stabilize the limited supermatrix.

Table 3. The ranking of key indicators for Smart healthcare information system.

\begin{tabular}{ccc}
\hline Key Indicators & Weights & Rank \\
\hline STI-1: Healthcare Data Platform & 0.008 & 9 \\
\hline STI-2: Innovation Application & 0.147 & 3 \\
\hline$H V C-1:$ User Acceptance with Usefulness & 0.070 & 8 \\
\hline$H V C-2:$ Business Value Creation & 0.215 & 2 \\
\hline$H V C-3:$ Doctor-Patient Relationship & 0.005 & 10 \\
\hline$F M B-1:$ Minimize Initial Investment Cost & 0.119 & 4 \\
\hline$F M B-2:$ Minimize Operating Costs & 0.106 & 5 \\
\hline$F M B-3:$ Minimize Equipment Maintenance Costs & 0.242 & 1 \\
\hline
\end{tabular}

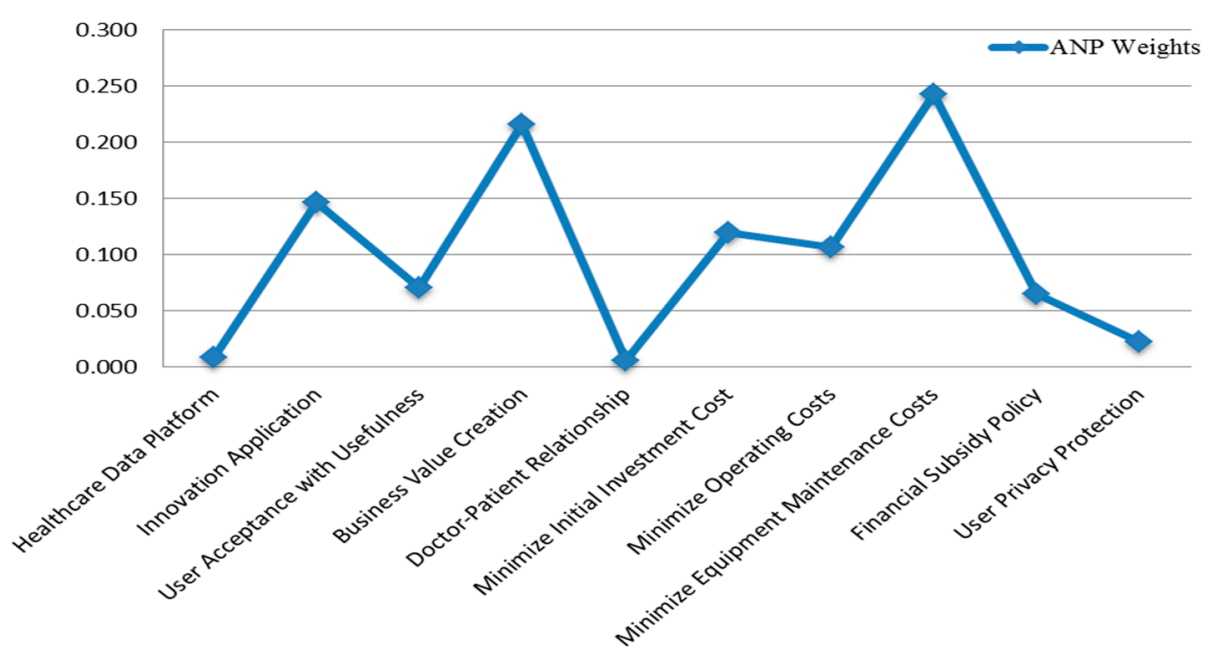

Figure 1. The weights of criteria for a Smart Healthcare Information System.

The ANP results indicated that the higher priority of evaluation criteria was Minimize Equipment Maintenance Costs (0.242) followed by Business Value Creation (0.215) > Innovation Application (0.147) $>$ Minimize Initial Investment Cost (0.119) > Minimize Operating Costs (0.106) > User Acceptance with Usefulness (0.070) > Financial Subsidy Policy (0.064) > User Privacy Protection (0.022) > Healthcare Data Platform (0.008) > Doctor-Patient Relationship (0.005). 
Step 3: Based on the VIKOR approach and rank alternatives.

Next, the weights of the evaluating criteria were incorporated into the VIKOR method to extract the compromise solution of the smart healthcare information system. The values of $S_{i}, R_{i}$, and $\mathbf{Q}$ were computed by selecting $v=0.5$. Table 4 shows that the Health Data Informational System was the closest to the ideal point. The performance variance rate was 0.176 . It showed that the Health Data Informational System still had some gaps (0.176) in the context of the goal value.

Table 4 . The value $S_{i}, R_{i}$, and $Q_{i}$, of SHIS.

\begin{tabular}{ccccc}
\hline SHIS Alternative & $S_{\boldsymbol{i}}$ & $\boldsymbol{R}_{\boldsymbol{i}}$ & $\boldsymbol{Q}_{\boldsymbol{i}}$ & Ranking \\
\hline Health Data Informational System & 0.151 & 0.200 & 0.176 & 1 \\
Hospital Administrative Information System & 0.435 & 0.600 & 0.518 & 3 \\
Hospital Operation Management System & 0.442 & 0.600 & 0.521 & 4 \\
Hospital Device and Drug Management System & 0.482 & 0.550 & 0.516 & 2 \\
\hline
\end{tabular}

Step 4: The direct costs and allocation of indirect costs according to $A B C$.

The main advantage of $\mathrm{ABC}$ is that it provides an accurate cost computation, especially under conditions in which activities vary and in which the indirect costs represent a substantial proportion of the total costs. In this study, the total costs of smart healthcare information system projects were divided into direct and indirect costs, as shown in Table 5.

Step 5: An optimal portfolio for the smart healthcare information system project using the Zero-One Goal Programming Model.

Utilizing mathematical programming for the simulation of the decision-making problem was appropriate for exploring solutions among the conflicting criteria and for reducing costs and time requirements effectively. This study employed the zero-one goal programming method that considered the MCDM compromise results and multiple resource requirement conditions to select the optimal portfolio. As the data show in Table 6, requirement resource constraints had the following obligatory goals:

(1) The total maximum budget amount of $\$ 20,000,000$ would be offered to the SHIS portfolio;

(2) An activity process improvement percentage of $180 \%$ would be the total maximum targeted to achieve the hospital efficiency during the system's life cycle;

(3) The longest implementation period would be 60 months. 
Table 5. ABC computations for Smart Healthcare Information System: Example Data.

\begin{tabular}{|c|c|c|c|c|c|c|c|c|c|c|c|c|c|c|}
\hline \multirow{4}{*}{$\begin{array}{l}\text { Required Resources } \\
\text { Life Cycle Activities }\end{array}$} & & \multirow{5}{*}{ Activity Drivers } & \multirow{2}{*}{\multicolumn{4}{|c|}{ Direct Material and Labor Costs= }} & \multicolumn{2}{|c|}{ SHIS 1} & \multicolumn{2}{|c|}{ SHIS 2} & \multicolumn{2}{|c|}{ SHIS 3} & \multicolumn{2}{|c|}{ SHIS 4} \\
\hline & & & & & & & \multicolumn{2}{|c|}{$6,130,000$} & \multicolumn{2}{|c|}{$2,420,000$} & \multicolumn{2}{|c|}{$3,150,000$} & \multicolumn{2}{|c|}{$4,250,000$} \\
\hline & & & \multicolumn{3}{|c|}{ Activity Cost (in Thousands) } & \multirow{2}{*}{$\begin{array}{c}\text { Total Activity } \\
\text { Costs(Unit Cost) }\end{array}$} & \multirow{2}{*}{$\begin{array}{l}\text { Activity Driver } \\
\text { Quantities }\end{array}$} & \multirow{2}{*}{$\begin{array}{l}\text { Activity } \\
\text { Cost }\end{array}$} & \multirow{2}{*}{$\begin{array}{l}\text { Activity Driver } \\
\text { Quantities }\end{array}$} & \multirow{2}{*}{$\begin{array}{l}\text { Activity } \\
\text { Cost }\end{array}$} & \multirow{2}{*}{$\begin{array}{l}\text { Activity Driver } \\
\text { Quantities }\end{array}$} & \multirow{2}{*}{$\begin{array}{l}\text { Activity } \\
\text { Cost }\end{array}$} & \multirow{2}{*}{$\begin{array}{l}\text { Activity Driver } \\
\text { Quantities }\end{array}$} & \multirow{2}{*}{$\begin{array}{c}\text { Activity } \\
\text { Cost }\end{array}$} \\
\hline & & & Labor & Materials & Equipment & & & & & & & & & \\
\hline & & & (a1) & (a2) & (a3) & $(\mathrm{a} 1)+(\mathrm{a} 2)+(\mathrm{a} 3)=(\mathrm{b})$ & (c1) & $(\mathbf{b})^{*}(\mathbf{c} 1)$ & (c2) & $(\mathbf{b})^{*}(\mathbf{c} 2)$ & (c3) & $(\mathbf{b})^{*}(\mathbf{c} 3)$ & (c4) & $(\mathbf{b})^{*}(\mathbf{c} 4)$ \\
\hline $\begin{array}{l}\text { (I) Initial Design phase } \\
\text { Planning design activity }\end{array}$ & {$[\mathrm{P}]$} & $\begin{array}{l}\text { Drawings of the } \\
\text { design }\end{array}$ & 300 & 250 & 150 & $\begin{array}{c}700,000 \\
(761)\end{array}$ & 150 & 114,130 & 200 & 152,174 & 320 & 243,478 & 250 & 190,217 \\
\hline Network environment activity & {$[\mathrm{A}]$} & $\begin{array}{c}\text { Hours of } \\
\text { Consultant }\end{array}$ & 150 & 200 & 300 & $\begin{array}{c}650,000 \\
(619)\end{array}$ & 380 & 235,238 & 160 & 121,739 & 200 & 152,174 & 310 & 235,870 \\
\hline $\begin{array}{l}\text { (II) Installation phase } \\
\text { System installation activity }\end{array}$ & [U] & $\begin{array}{l}\text { Hours of } \\
\text { Consultant }\end{array}$ & 1200 & 1405 & 2000 & $\begin{array}{l}4,605,000 \\
(3936)\end{array}$ & 110 & 432,949 & 400 & 247,619 & 350 & 216,667 & 310 & 191,905 \\
\hline Staff training activity & [B] & $\begin{array}{l}\text { Lessons of the } \\
\text { course }\end{array}$ & 500 & 300 & 300 & $\begin{array}{c}1,100,000 \\
(1384)\end{array}$ & 145 & 200,629 & 290 & $1,141,410$ & 200 & 787,179 & 160 & 629,744 \\
\hline $\begin{array}{l}\text { (III) Operation phase } \\
\text { Maintenance and repair } \\
\text { activity }\end{array}$ & [U] & $\begin{array}{l}\text { Hours of } \\
\text { Consultant }\end{array}$ & 2100 & 1100 & 1500 & $\begin{array}{l}4,700,000 \\
(2686)\end{array}$ & 360 & 966,857 & 460 & 636,478 & 500 & 691,824 & 430 & 594,969 \\
\hline Data analysis activity & {$[\mathrm{A}]$} & $\begin{array}{c}\text { Hours of actual } \\
\text { usage }\end{array}$ & 350 & 250 & 700 & $\begin{array}{c}1,300,000 \\
(1776)\end{array}$ & 222 & 394,262 & 200 & 537,143 & 120 & 322,286 & 190 & 510,286 \\
\hline $\begin{array}{l}\text { (IV) Improvement phase } \\
\text { System module upgrade } \\
\text { activity }\end{array}$ & {$[\mathrm{U}]$} & $\begin{array}{c}\text { Number of } \\
\text { delivery packages }\end{array}$ & 1100 & 2000 & 1400 & $\begin{array}{l}4,500,000 \\
(4918)\end{array}$ & 210 & $1,032,787$ & 160 & 284,153 & 255 & 452,869 & 290 & 515,027 \\
\hline Management control activity & {$[\mathrm{A}]$} & $\begin{array}{c}\text { Number of } \\
\text { change requests }\end{array}$ & 450 & 700 & 800 & $\begin{array}{c}1,950,000 \\
(2468)\end{array}$ & 140 & 345,570 & 200 & 355,191 & 190 & 337,432 & 260 & 461,749 \\
\hline \multicolumn{7}{|c|}{ Total Cost $=$ Total direct cost + Total indirect cost } & \multicolumn{2}{|c|}{$9,852,422$} & \multicolumn{2}{|l|}{$5,895,907$} & \multicolumn{2}{|c|}{$6,353,908$} & \multicolumn{2}{|c|}{$7,579,766$} \\
\hline
\end{tabular}

Note: [U]: Unit level; [B]: Batch level; [P]: Project level; [A] Artificial intelligence level. 
Table 6. Resource requirements and essential limitations of SHIS.

\begin{tabular}{cccccc}
\hline Resource Requirements & SHIS 1 & SHIS 2 & SHIS 3 & SHIS 4 & Goal (bi) \\
\hline Activity-Based Costing budget planning (in thousands) & 9852 & 5896 & 6354 & 7580 & 20000 \\
Activity Process improvement (percentage) & 85 & 85 & 90 & 90 & 180 \\
Implementation period (months) & 24 & 20 & 30 & 36 & 60 \\
VIKOR weights & 0.176 & 0.518 & 0.521 & 0.516 & \\
\hline
\end{tabular}

Finally, the resource requirement and essential limitations of SHIS were incorporated into the mathematical optimization model. The final ZOGP model formulation is shown in Table 7, presenting the priority of VIKOR weights and $d_{1}^{+}$and $d_{1}^{-}$, respectively. Meanwhile, the binary variables were SHIS 1 (Health Data Informational System), SHIS 2 (Hospital Administrative Information System, SHIS 3 (Hospital Operation Management System), and SHIS 4 (Hospital Device and Drug Management System). The final optimal portfolio of SHIS resulting from ZOGP under resource constraints indicated that the Health Data Informational System and the Hospital Device and Drug Management System would be selected. 
Table 7. The ZOGP model formulation.

\begin{tabular}{|c|c|}
\hline ZOGP Model Formulation & Goal \\
\hline \multicolumn{2}{|l|}{ Minimize $\mathrm{VC}=$} \\
\hline$P_{1}\left(d_{1}^{+}+d_{2}^{+}+d_{3}^{+}\right)$ & $\begin{array}{l}\text { Satisfying each mandated resource constraint for the smart healthcare information } \\
\text { system project. }\end{array}$ \\
\hline$P_{2}\left(0.176 d_{4}^{-}+0.518 d_{5}^{-}+0.521 d_{6}^{-}+0.516 d_{7}^{-}\right)$ & Selecting the ranking weights for the smart healthcare information system from VIKOR. \\
\hline $\begin{array}{l}\text { Subject to } \\
9852 \text { SHIS }_{1}+5896 \text { SHIS }_{2}+6354 \text { SHIS }_{3}+7580 \text { SHIS }_{4}-d_{1}^{+}+d_{1}^{-}=20,000 \\
85 \text { SHIS }_{1}+85 \text { SHIS }_{2}+90 \text { SHIS }_{3}+90 \text { SHIS }_{4}-d_{2}^{+}+d_{2}^{-}=180 \\
24 \text { SHIS }_{1}+20 \text { SHIS }_{2}+30 \text { SHIS }_{3}+36 \text { SHIS }_{4}-d_{3}^{+}+d_{3}^{-}=60 \\
\text { SHIS }_{2}+d_{5}^{-}=1 \\
\text { SHIS }_{3}+d_{6}^{-}=1 \\
\text { SHIS }_{4}+d_{7}^{-}=1 \\
\text { SHIS }_{j}=0 \text { or } 1 \text { for } j=1,2,3,4\end{array}$ & $\begin{array}{l}\text { Avoiding over-utilizing maximum budgeted costs. } \\
\text { Avoiding over-utilizing maximum percentage for activity process improvement. } \\
\text { Avoiding over-utilizing the maximum implementation period. } \\
\text { Selecting SHIS for Health Data Informational System. } \\
\text { Selecting SHIS for Hospital Administrative Information System. } \\
\text { Selecting SHIS for Hospital Operation Management System. } \\
\text { Selecting SHIS for Hospital Device and Drug Management System. }\end{array}$ \\
\hline \multicolumn{2}{|c|}{$\begin{array}{l}\text { Formulation Results } \\
\qquad \text { SHIS }_{1}=1, \text { SHIS }_{2}=0, \text { SHIS }_{3}=0, \text { SHIS }_{4}=1 \\
\qquad d_{1}^{-}=2568, d_{1}^{+}=0, d_{2}^{-}=5, d_{2}^{+}=0, d_{3}^{-}=6, d_{3}^{+}=0\end{array}$} \\
\hline
\end{tabular}




\section{Discussions}

The development and evaluation of sustainable smart healthcare information system is a great significance to respond the smart city policy and to alleviate the healthcare resource problem caused by healthcare information asymmetry. The accurate cost evaluation of smart healthcare information portfolio strategy can achieve optimal strategy planning.

According to the (D-R) values by the DEMATEL method, this study found that the major influencing perspectives are Financial Management Benefit (FMB) and Government Policy Support (GPS) for SHIS selection. The ANP results indicated that the ranking of key indicators for SHIS were Minimize Equipment Maintenance Costs > Business Value Creation > Innovation Application > Minimize Initial Investment Cost $>$ Minimize Operating Costs $>$ User Acceptance with Usefulness > Financial Subsidy Policy $>$ User Privacy Protection $>$ Healthcare Data Platform $>$ Doctor-Patient Relationship. Finally, the ranking SHIS strategy by VIKOR method reveal that Health Data Informational System $>$ Hospital Device and Drug Management System $>$ Hospital Administrative Information System $>$ Hospital Operation Management System.

Incorporating the $\mathrm{ABC}$ evaluation and combine resource requirement and limitation within the hybrid decision process. Lastly, the optimal portfolio of SHIS under resource limitations (Activity-Based Costing budget planning, Activity Process improvement and Implementation period) uses the ZOGP model and consider the VIKOR weights with hybrid decision model.The results indicate that Health Data Informational System and Hospital Device and Drug Management System would be selected for the for the smart healthcare information portfolio strategy through the integrated decision model.

\section{Concluding Remarks}

In the interest of smart city mainstream development, Taiwan has put abundant resources into smart technology and policy regulations to encourage the development of smart industry. In order to achieve the Sustainable Development Goals and Corporate Social Responsibility (CSR) practices, the eHealth industry chain development promotes the population obtaining better healthcare services. This study provided an integrated MCDM and Activity-Based Costing budget plan for evaluating the smart healthcare information system of the smart hospital.

The results showed that Government Policy Support and Financial Management Benefit were the major factors for achieving the smart healthcare development goals. Furthermore, considering the evaluation criteria interrelationship, the ANP analysis findings implied that the smart healthcare information industry should focus its attention on minimizing equipment maintenance costs in the SHIS life cycle; business value creation also was important so that the information system could provide the process core value promotion. From the smart healthcare information system lifecycle basis, the process activity value maximum was worthy of evaluation by Activity-Based Costing (ABC) techniques. According to the smart healthcare information system characteristic, the activity hierarchy, divided into Unit-, Batch-, Project-, and Artificial Intelligence level, was combined with the life cycle of SHIS. Hence, the budget planning was measured by Activity-Based Costing and satisfied each resource constraint by a mathematical programming decision model for SHIS portfolios.

The primary contribution of the study is its benefit for academia, industry and policy makers by providing a hybrid decision model integrating $\mathrm{ABC}$ and resource constraints into SHIS portfolio selection. For academia, this study contributed to the management accounting innovation development-sustainable city and operation research (OR) literature, especially with respect to the incorporation of the smart industry characteristic measurement into a smart healthcare information system, by utilizing the MCDM decision and Mathematical Programming model to provide the solution that would reduce the cost of healthcare without sacrificing the quality of patient care. For healthcare industry, this model can help decision-makers accurately understand how to allocate resources and improve inefficient resource input in each activity via appropriate cost drivers for the smart healthcare information strategy implementation. As for policy makers, the optimal SHIS 
portfolio selection model as proposed takes into consideration the advantages of the MCDM method and mathematical programming.

Author Contributions: Conceptualization, C.-H.Y.; methodology, C.-H.Y., H.-L.L. and W.-H.T.; software, C.-H.Y. and H.-L.L.; validation, W.-H.T.; formal analysis, C.-H.Y., H.-L.L. and W.-H.T.; data curation, C.-H.Y. and W.-H.T.; writing-original draft preparation, C.-H.Y., H.-L.L. and W.-H.T.; writing-review and editing, C.-H.Y., S.C. and W.-H.T.; supervision, C.-H.Y. and W.-H.T.; project administration, H.-L.L. and S.C.; funding acquisition, C.-H.Y. and W.-H.T. All authors have read and agreed to the published version of the manuscript.

Funding: This research was funded by the Ministry of Science and Technology of Taiwan for financially supporting this research under Grant MOST 107-2914- I- 606- 005- A1 and MOST 109-2410-H-008-029-MY2.

Conflicts of Interest: The authors declare that they have no known competing financial interests or personal relationships that could have appeared to influence the work reported in this paper.

\section{References}

1. World Health Organization. Framework and Standards for Country Health Information Systems; World Health Organization: Geneva, Switzerland, 2008.

2. Catarinucci, L.; De Donno, D.; Mainetti, L.; Palano, L.; Patrono, L.; Stefanizzi, M.L.; Tarricone, L. An IoT-aware architecture for smart healthcare systems. IEEE Internet Things J. 2015, 2, 515-526. [CrossRef]

3. Sligo, J.; Gauld, R.; Roberts, V.; Villa, L. A literature review for large-scale health information system project planning, implementation and evaluation. Int. J. Med Inform. 2017, 97, 86-97. [CrossRef] [PubMed]

4. Feng, Y.; Hong, Z.; Tian, G.; Li, Z.; Tan, J.; Hu, H. Environmentally friendly MCDM of reliability-based product optimisation combining DEMATEL-based ANP, interval uncertainty and Vlse Kriterijumska Optimizacija Kompromisno Resenje (VIKOR). Inf. Sci. 2018, 442, 128-144. [CrossRef]

5. Deng, D.; Wen, S.; Chen, F.H.; Lin, S.L. A hybrid multiple criteria decision making model of sustainability performance evaluation for Taiwanese Certified Public Accountant firms. J. Clean. Prod. 2018, 180, 603-616. [CrossRef]

6. Liu, K.M.; Lin, S.H.; Hsieh, J.C.; Tzeng, G.H. Improving the food waste composting facilities site selection for sustainable development using a hybrid modified MADM model. Waste Manag. 2018, 75, 44-59. [CrossRef]

7. Cocchia, A. Smart and digital city: A systematic literature review. In Smart City; Springer: Cham, Germany, 2014; pp. 13-43.

8. Albino, V.; Berardi, U.; Dangelico, R.M. Smart cities: Definitions, dimensions, performance, and initiatives. Journal of Urban Technology. 2015, 22, 3-21. [CrossRef]

9. Organization for Economic Cooperation and Development. "Smart cities as engines for growth in ASIA". Emerging Markets Network, OECD Development Centre, 2020; pp. 15-16. Available online: https: //www.oecd.org/dev/EMnet-Asia-Policy-Note-2020.pdf (accessed on 25 October 2020).

10. Haux, R. Health information systems-past, present, future. Int. J. Med Inform. 2006, 75, 268-281. [CrossRef]

11. Kim, Y.G.; Jung, K.; Park, Y.T.; Shin, D.; Cho, S.Y.; Yoon, D.; Park, R.W. Rate of electronic health record adoption in South Korea: A nation-wide survey. Int. J. Med Inform. 2017, 101, 100-107. [CrossRef]

12. Zhang, Y.; Qiu, M.; Tsai, C.W.; Hassan, M.M.; Alamri, A. Health-CPS: Healthcare cyber-physical system assisted by cloud and big data. IEEE Syst. J. 2015, 11, 88-95. [CrossRef]

13. Tuli, S.; Tuli, S.; Wander, G.; Wander, P.; Gill, S.S.; Dustdar, S.; Sakellariou, R.; Rana, O. Next generation technologies for smart healthcare: Challenges, vision, model, trends and future directions. Internet Technol. Lett. 2020, 3, e145. [CrossRef]

14. Chae, Y.M.; Yoo, K.B.; Kim, E.S.; Chae, H. The adoption of electronic medical records and decision support systems in Korea. Healthc. Inform. Res. 2011, 17, 172-177. [CrossRef] [PubMed]

15. Handayani, P.W.; Hidayanto, A.N.; Pinem, A.A.; Hapsari, I.C.; Sandhyaduhita, P.I.; Budi, I. Acceptance model of a hospital information system. Int. J. Med Inform. 2017, 99, 11-28. [CrossRef] [PubMed]

16. Wang, Y.; Kung, L.; Wang, W.Y.C.; Cegielski, C.G. An integrated big data analytics-enabled transformation model: Application to health care. Inf. Manag. 2018, 55, 64-79. [CrossRef]

17. Liang, C.; Gu, D.; Tao, F.; Jain, H.K.; Zhao, Y.; Ding, B. Influence of mechanism of patient-accessible hospital information system implementation on doctor-patient relationships: A service fairness perspective. Inf. Manag. 2017, 54, 57-72. [CrossRef] 
18. Jonas, J.M.; Roth, A. Stakeholder integration in service innovation-an exploratory case study in the healthcare industry. Int. J. Technol. Manag. 2017, 73, 91-113. [CrossRef]

19. Mohamadali, N.A.; Zahari, N.A. The Organization Factors as Barrier for Sustainable Health Information Systems (HIS)-A Review. Procedia Comput. Sci. 2017, 124, 354-361. [CrossRef]

20. Ker, J.I.; Wang, Y.; Hajli, N. Examining the impact of health information systems on healthcare service improvement: The case of reducing in patient-flow delays in a US hospital. Technol. Forecast. Soc. Chang. 2018, 127, 188-198. [CrossRef]

21. Kshetri, N. The evolution of the internet of things industry and market in China: An interplay of institutions, demands and supply. Telecommun. Policy 2017, 41, 49-67. [CrossRef]

22. Ahmadi, H.; Nilashi, M.; Shahmoradi, L.; Ibrahim, O. Hospital Information System adoption: Expert perspectives on an adoption framework for Malaysian public hospitals. Comput. Hum. Behav. 2017, 67, 161-189. [CrossRef]

23. World Health Organization. Global Diffusion of eHealth: Making Universal Health Coverage Achievable: Report of the Third Global Survey on eHealth; World Health Organization: Geneva, Switzerland, 2017.

24. Cooper, R.; Kaplan, R.S. Measure costs right: Make the right decisions. Harv. Bus. Rev. 1988, 66, 96-103.

25. Al-Sayed, M.; Dugdale, D. Activity-based innovations in the UK manufacturing sector: Extent, adoption process patterns and contingency factors. The British Accounting Review. 2016, 48, 38-58. [CrossRef]

26. Cannavacciuolo, L.; Illario, M.; Ippolito, A.; Ponsiglione, C. An activity-based costing approach for detecting inefficiencies of healthcare processes. Bus. Process Manag. J. 2015, 21, 55-79. [CrossRef]

27. French, K.E.; Guzman, A.B.; Rubio, A.C.; Frenzel, J.C.; Feeley, T.W. Value based care and bundled payments: Anesthesia care costs for outpatient oncology surgery using time-driven activity-based costing. In Healthcare; Elsevier: Amsterdam, The Netherlands, 2016; Volume 4, pp. 173-180.

28. Gabus, A.; Fontela, E. The DEMATEL observer; Battelle Geneva Research Center: Geneva, Switzerland, 1976.

29. Saaty, T.L. Decision Making with Dependence and Feedback: The Analytic Network Process; RWS Publications: Pittsburgh, PA, USA, 2001; Volume 7, pp. 557-570.

30. López-Ospina, H.; Quezada, L.E.; Barros-Castro, R.A.; Gonzalez, M.A.; Palominos, P.I. A method for designing strategy maps using DEMATEL and linear programming. Manag. Decis. 2017, 55, 1802-1823. [CrossRef]

31. Tavana, M.; Yazdani, M.; Di Caprio, D. An application of an integrated ANP-QFD framework for sustainable supplier selection. Int. J. Logist. Res. Appl. 2017, 20, 254-275. [CrossRef]

32. Opricovic, S. Multicriteria optimization of civil engineering systems; Faculty of Civil Engineering: Belgrade, Serbia, 1998; Volume 2, pp. 5-21.

33. Charnes, A.; Cooper, W.W.; Ferguson, R.O. Optimal estimation of executive compensation by linear programming. Manag. Sci. 1955, 1, 138-151. [CrossRef]

Publisher's Note: MDPI stays neutral with regard to jurisdictional claims in published maps and institutional affiliations.

(C) 2020 by the authors. Licensee MDPI, Basel, Switzerland. This article is an open access article distributed under the terms and conditions of the Creative Commons Attribution (CC BY) license (http://creativecommons.org/licenses/by/4.0/). 